\title{
ПОСТКЕЙНСИАНСКИЕ МОДЕЛИ ЭКОНОМИЧЕСКОГО РОСТА В КОНТЕКСТЕ ПРОБЛЕМ СТРАН С РАЗВИВАЮЩИМИСЯ РЫНКАМИ
}

\author{
(c) 2018 Вэнь Гуаньсюй \\ аспирант кафедры экономической теории и менеджмента \\ Московский педагогический государственный университет \\ 119991, Москва, ул. Малая Пироговская, д. 1, стр. 1 \\ E-mail: venguanxu@mail.ru \\ (C) 2018 Лихачев Михаил Олегович \\ доктор экономических наук, доцент \\ профессор кафедры экономической теории и менеджмента \\ Московский педагогический государственный университет \\ 119991, Москва, ул. Малая Пироговская, д. 1, стр. 1 \\ E-mail: olegmix71@mail.ru
}

В статье рассматривается структура посткейнсианских моделей экономического роста и, в частности модели Н. Калдора. Авторы статьи рассматривают теоретические выводы данных моделей в соотношении с проблемами современных стран с развивающимися рынками и обосновывают вывод о том, что посткейнсианские модели экономического роста адекватно отражают важнейшие характеристики процессов экономического роста развивающихся стран.

Ключевые слова: посткейнсианство, экономический рост, типология экономического роста, посткейнсианские модели роста, модель Н. Калдора, устойчивые темпы роста, развивающиеся рынки, развивающиеся страны.

Посткейнсианская теория экономического роста представляет собой совокупность теоретических моделей, стремящихся совместить кейнсианские идеи относительно ведущей роли эффективного спроса с представлениями об относительно устойчивом характере роста в рыночной экономике [1;2]. В этом заключается преодоление основного порока раннекейнсианских моделей экономического роста, в первую очередь, моделей Р. Харрода и Е. Домара, которые предполагали единственную устойчивую траекторию роста, которая была нереализуема на практике $[1 ; 2]$. Такой теоретический подход не позволял объяснить, почему рыночная экономика, несмотря на неполное использование ресурсов и периодические кризисы, все же демонстрирует положительные темпы экономического роста на протяжении длительного времени [4]. Этот же вопрос уместен и применительно к странам с развивающимися рынками, которые также, несмотря на многочисленные трудности и проблемы демонстрируют устойчивую положительную экономическую динамику на протяжении целого исторического периода. Посткейтсианские модели экономического роста позволяют согласовать этот эмпирический факт с теоретическими принципами кейнсианства [5; 7]. В этом можно убедиться на примере одной из ведущих посткейнсианских моделей экономического роста - модели Н. Калдора [3; 10].

\section{Модель Н. Калдора}

Базовое уравнение модели Н. Калдора определяет стоимостную структуру производства [3; 6]:

$Q p=(d+\pi) K p+w a Q+w b K$

Где $\mathrm{Q}$ - реальный объем производства, $\mathrm{K}$ - запас основного капитала, $\mathrm{p}$ - уровень цен, $\mathrm{d}$ - норма амортизации, $\pi$ - норма прибыли, a - затраты ручного труда в расчете на единицу выпуска, $b$ - затраты добавочного труда в расчете на единицу капитального оборудования, w ставка номинальной заработной платы. Деление обеих частей этого уравнения на Qp дает:

$$
1=(d+\pi+\omega b) K / Q+\omega a ;
$$

где $\omega$ - ставка реальной заработной платы. Отношение капитал/выпуск (K/Q) в любой момент времени определяется соотношением двух факторов - эффективности производства 
и уровня эффективного спроса, определяющего объем использования производственных мощностей:

$$
\frac{K}{Q}=\frac{K Q_{c}}{Q_{c} Q}=\frac{v}{u}
$$

где Qc - потенциально возможный объем выпуска при данном объеме капитального оборудования, $v=\mathrm{K} / \mathrm{Qc}-$ коэффициент капитал/ производственные мощности, $u=\mathrm{Q} / \mathrm{Qc}-$ коэффициент загрузки производственных мощностей.

Норма амортизации рассматривается как величина линейно зависимая от степени загрузки производственных мощностей:

$$
\mathrm{d}=\delta+\varepsilon \mathrm{u} ; \delta<1, \varepsilon>0, \varepsilon+\delta<1 ;
$$

где $\delta$ - независимый компонент амортизации, а $\varepsilon-$ коэффициент, характеризующий зависимость нормы амортизации от степени использования ресурсов. С учетом этого, исходное выражение может быть записано как:

$$
1=(\delta+\pi+\omega b) \frac{v}{u}+\varepsilon v+\omega a ;
$$

Отсюда норму прибыли можно выразить как:

$$
\pi=[1-(\varepsilon v+\omega a)] \frac{u}{v}-(\delta+\omega b)
$$

Это выражение определяет граничные условия модели Н. Калдора, то есть набор значений нормы прибыли, ставки заработной платы и степени использования производственных мощностей. Отсюда, приравняв норму прибыли к нулю, можно выразить минимальное значение степени использования ресурсов, обеспечивающее безубыточность производства:

$$
u^{\prime}=\frac{(\delta+\omega b) v}{1-(\varepsilon v+\omega a)} ;
$$

На базе выражения для нормы прибыли определяется также функция сбережений, поскольку в модели Н. Калдора, как большинстве посткейнсианских моделей, предполагается, что сбережения делаются только из прибыли. Исходя из этого, объем сбережений можно представить как:

$$
\mathrm{S}=\mathrm{s} \pi \mathrm{K}
$$

Отсюда можно выразить темп роста сбережений:

$$
\sigma=\frac{S}{K}=s \pi=s\left([1-(\varepsilon v+\omega a)] \frac{u}{v}-(\delta+\omega b)\right) ;
$$

Долгосрочное равновесие и устойчивый темп роста будут поддерживаться при условии, что темп роста сбережений будет совпадать с темпом роста инвестиций. Поскольку ожидаемая норма прибыли находится в обратной зависимости от реальной заработной платы и величины затрат ручного труда на единицу выпуска, инвестиционная функция в модели Н. Калдора имеет вид:

$$
\imath=\alpha-\beta \omega \mathrm{a}+\gamma \mathrm{u}
$$

где $\beta$ - коэффициент, выражающий эту обратную зависимость.

Сбалансированный рост в экономике будет иметь место только в случае, если сбережения на единицу капитального запаса будут равны инвестициям на единицу капитального запаса. Исходя из этого условие, обеспечивающее равновесный рост экономики, может быть записано как равенство функции сбережения инвестиционной функции:

$$
s\left([1-(\varepsilon v+\omega a)] \frac{u}{v}-(\delta+\omega b)\right)=\alpha-\beta \omega a+\gamma u ;
$$

Преобразуя это выражение можно выразить отсюда зависимость между равновесными значениями степени использования производственных мощностей и уровнем реальной заработной платы:

$$
u=\frac{\alpha-\beta \omega a+s(\delta+\omega b)}{[1-(\varepsilon v+\omega a)] \frac{s}{v}-\gamma}
$$

Таким образом, каждому равновесному значению темпа роста соответствует равновесное значение коэффициента использования производственных мощностей и реальной заработной платы.И поскольку коэффициент использования мощностей имеет ограниченный набор потенциальных значений ( $\left.\mathfrak{u}^{\prime}<\mathrm{u} \leq 1\right)$, то при условии, что все остальные параметры заданы, можно определить набор возможных равновесных темпов роста экономики и, соответствующих им, уровней реальной заработной платы. В результате, получим набор состояний долгосрочного равновесия для любой экономической системы 
с заданным набором экзогенных параметров. K тому же все кроме одного из этих вариантов (варианта для $\mathrm{u}=1$ ) предполагают неполное использование производственных мощностей, что соответствует кейнсианским представлениям о равновесии при неполной занятости.

Таким образом, модель Н. Калдора, в отличие от модели Р. Харрода и Е. Домара, предполагает существование не одной, а определенного множества траекторий равновесного роста, которые различаются между собой уровнем реальной заработной платы и уровнем использования производственных мощностей. Поэтому применительно к данной модели, естественно, возникает вопрос об оптимизации, то есть об определении наилучшей траектории равновесного роста. Однако, также неизбежно встает вопрос о выборе параметра, который должен достигать максимума при реализации оптимального варианта [11; 19]. В модели Н. Калдора можно выделить, по крайней мере, четыре таких параметра: объем потребления, степень использования производственных мощностей и уровень реальной заработной платы и норма прибыли, которая напрямую связана с темпом роста объемов производства в рассматриваемой системе. Причем в зависимости от величины постоянных параметров модели цель максимизации одного из этих параметров может совпадать или противоречить целям максимизации остальных.

Потребление в модели Н. Калдора можно представить как разность реального объема производства и объема сбережений в каждый момент времени. Обе эти величины являются функцией от объема накопленного капитала и их разность, исходя из базовых уравнений, имеет вид:

$$
C=\left(\frac{u}{v}(1-s(1-\omega a))+s(\varepsilon u+\delta+\omega b)\right) K
$$

Дифференцируя это выражение по величине реальной заработной платы и степени использования производственных мощностей, получим:

$$
d C=\left(\left(\frac{u}{v} s a+b\right) \Delta \omega+\frac{s}{v}\left(\frac{1}{s}+\varepsilon v-(1-\omega a)\right) \Delta u\right)
$$

Зависимость объема потребления от величины реальной заработной платы и степени использования производственных мощностей является положительной. Это означает, что с ростом реальной заработной платы и степени использования производственных мощностей объем потребления при любой величине накопленного капитала будет увеличиваться. Однако, поскольку при выборе оптимальной траектории равновесного роста рассматриваются только равновесные значения степени использования производственных мощностей и уровня реальной заработной платы, которые связаны между собой определенной зависимостью, можно элиминировать дону из этих величин, выразив ее через изменение другой величины. Если таким образом элиминируется изменение степени использования производственных мощностей как величина, зависимая от изменения уровня реальной заработной платы, то предыдущее выражение может быть переписано как:

$$
\frac{d C}{d \omega}=K\left(\left(\frac{u}{v} s a+b\right)+\frac{s}{v}\left(\frac{1}{s}+\varepsilon v-(1-\omega a)\right) \frac{d u}{d \omega}\right)
$$

Для определения разных направлений оптимизации долгосрочного равновесия это выражение надо сопоставить с дифференциалом нормы прибыли по реальной заработной плате и степени использования мощностей. Причем в этом выражении также можно элиминировать значение изменения степени использования мощностей, представив его как величину зависимую от изменения уровня реальной заработной платы:

$$
\frac{d \pi}{d \omega}=\left((1-(\varepsilon v+\omega a)) \frac{1}{v} \frac{d u}{d \omega}-\left(\frac{u}{v} a+b\right)\right)
$$

Дальнейший анализ этих выражений позволяет развить типологию экономического роста, которая может быть применима к анализу реальных процессов экономического роста в различных странах с развивающимися рынками.

Типология экономического роста в модели Н. Калдора и развивающиеся рынки

Модель Н. Калдора предполагает четыре возможных варианта развития процессов экономического роста, то есть позволяет выделить четыре различных типа экономического роста, различающихся по взаимосвязям основных параметров и оптимизационным критериям [12].

Первый тип характеризуется положительной зависимостью между равновесными значениями реальной заработной платы и степени использования мощностей. Причем величина, характеризующая эту зависимость, имеет достаточно высокое значение, так что зависимость нормы прибыли от величины реальной заработной платы и степени использования ресурсов 
также является положительной. Этот вариант является наиболее предпочтительным, поскольку допускает одновременную максимизацию всех четырех величин. Все критерии оптимальности в этом случае совпадают и есть возможность определить траекторию роста, которая является оптимальной со всех точек зрения, то есть гарантирует максимальную норму прибыли, максимальный темп роста, а также максимальное потребление, реальную заработную плату и степень использования производственных мощностей.

Второй тип также характеризуется положительной зависимостью между равновесными значениями реальной заработной платы и степенью использования производственных мощностей. Однако, величина, характеризующая эту зависимость, принимает настолько низкие значения, что зависимость нормы прибыли от величины реальной заработной платы и степени использования производственных мощностей является отрицательной. В этом случае максимизировать потребление, реальную заработную плату и степень использования ресурсов можно только за счет минимизации нормы прибыли и темпа роста. И, наоборот, максимизация нормы прибыли и темпа роста может достигаться только за счет минимизации потребления, реальной заработной платы и степени использования производственных мощностей. При таком варианте возникает конфликт критериев оптимальности. Траектория роста оптимальная с точки зрения максимизации потребления, реальной заработной платы и степени использования производственных мощностей не будет оптимальной с точки зрения максимизации нормы прибыли и темпа роста и, наоборот. Двойственность оптимизационного решения создает почву для конфликта социальных интересов и переводит проблему оптимизации в плоскость общественного выбора на базе сложившихся целей и приоритетов экономического развития.

Третий тип характеризуется отрицательной зависимостью между равновесными значениями степени использования производственных мощностей и уровня реальной заработной платы. Причем абсолютное значение величины, характеризующей эту зависимость достаточно мало, так что зависимость объема потребления от уровня реальной заработной платы является положительной. В этом случае цели максимизации потребления и уровня реальной заработ- ной платы будут противоречить цели максимизации нормы прибыли, темпа роста и степени использования производственных мощностей. Следовательно, и для этого типа системы будет характерна двойственность оптимизационного решения. Траектория равновесного роста оптимальная с точки зрения максимизации потребления и уровня реальной заработной платы не будет оптимальной с точки зрения максимизации нормы прибыли, темпа роста и степени использования производственных мощностей и, наоборот - траектория роста оптимальная с точки зрения максимизации нормы прибыли, темпа роста и степени использования производственных мощностей будет неоптимальна с точки зрения максимизации уровня реальной заработной платы и объема потребления.

Четвертый тип также характеризуется отрицательной зависимостью между равновесными значениями степени использования производственных мощностей и уровня реальной заработной платы. Однако, абсолютное значение величины, характеризующей эту зависимость достаточно велико, чтобы зависимость объема потребления от уровня реальной заработной платы стала отрицательной. В этом случае цель максимизации уровня реальной заработной платы будет противоречить не только целям максимизации нормы прибыли, темпа роста и степени использования производственных мощностей, но и цели максимизации потребления. Следовательно, траектория равновесного роста оптимальная с точки зрения максимизации реальной заработной платы будет неоптимальная с точки зрения максимизации потребления, нормы прибыли, темпа роста и степени использования производственных мощностей. Конфликтность интересов при таком типе функционирования экономической системы будет наивысшей.

Эти типы экономического роста могут быть использованы для анализа реальных процессов экономического роста в странах с развивающимися рынками [9]. Однако не все они являются в одинаковой степени релевантными по отношению к экономическим реалиям этих стран. Первый тип, представляющий собой наиболее гармоничный вариант экономического роста и развития и роста, очевидно, не может рассматриваться в качестве релевантного по отношению к развивающимся рынкам с их конфликтными и противоречиями. Второй тип, характеризую- 
щийся конфликтом между интересами роста потребления и реальной заработной платы, с одной стороны, и интересами увеличения нормы прибыли и темпов роста - с другой, представляется наиболее релевантным для описания начальных стадий экономического роста связанных с интенсивным процессом индустриализации [11]. В этот период резкое увеличение инвестиций достигается за счет ограничения потребления и использования ресурсов дешевой рабочей силы. В результате резко возрастет норма прибыли и инвестиционная привлекательность новых экономических проектов. Однако, такой путь развития, неизбежно, вызывает социальную напряженность, которая должна смягчаться путем определенных социально-политических мер.

Третий тип экономического роста является родственным по отношению ко второму, но при этом является еще более релевантным для описания процессов роста в странах с развивающимися рынками, поскольку связывает максимизацию нормы прибыли и темпов роста с максимизацией степени использования производственных мощностей и, следовательно, уровня занятости. Это также характерно для процесса быстрой индустриализации, когда развитие производства сопровождается массовым созданием новых рабочих мест, приводя при этом к снижению уровня реальной заработной платы и сокращению потребления. Рост уровня занятости в таких условиях выступает в качестве амортизатора негативных процессов, связанных со снижением потребления и снижает социальную напряженность, поскольку создает у большинства населения уверенность в относительной стабильности их сравнительно скромного уровня благосостояния. Поэтому при таком варианте развития гораздо легче сбалансировать интересы развития экономики с текущими интересами большинства общества [8].

Четвертый тип экономического роста, выделяемый на основе модели Н. Калдора, также может быть релевантным для некоторых стран с развивающимися рынками. Этот тип экономического роста предполагает возможность максимизации нормы прибыли, темпов роста уровня занятости и потребления за счет минимизации уровня реальной заработной платы. Следовательно, высокие темпы роста и связанные с ним преференции обеспечиваются исключительно за счет ресурсов дешевой рабочей силы. Однако, исчерпание этих ресурсов грозит ростом уровня реальной заработной планы, что ведет к снижению темпов роста, нормы прибыли, уровня занятости и потребления, что означает общее ухудшение экономической ситуации и, как следствие, долгосрочную стагнацию.

Относительная устойчивость темпов роста и многовариантность экономического развития, предполагаемая в посткейнсианских моделях экономического роста и, в частности, в модели Н. Калдора, позволяет рассматривать их в качестве наиболее адекватного инструмента для анализа процессов экономического роста в странах с развивающимися рынками.

\section{Библиографический список}

1. Блауг М. Экономическая мысль в ретроспективе. Москва. 1994.

2. Вайнтрауб С. Посткейнсианские теории экономического роста. / Современная экономическая мысль. Москва. 1981.

3. Кури Х.Д. Технические изменения, рост и распределение: стабильный подход к нестабильному росту/Капитал, распределение, эффективный спрос. Москва. 1998.

4. Столерю Л. Равновесие и экономический рост (принципы макроэкономического анализа). Москва. 1974.

5. Asensio A., Lang D. Charles $S$. Post Keynesian modeling: where are we, and where are we going to? // Journal of Post Keynesian Economics. Volume 34, 2012. Issue 3. pp. 393-412.

6. Bairam E.I. Kaldor's technical progress function revisited // Applied Economics Letters Volume 2, 1995 - Issue 9. pp. 302-304.

7. Boylan T. A., O’Gorman P.F. Kaldor on Debreu: The Critique of General Equilibrium Reconsidered // Review of Political Economy. Volume 21, 2009 - Issue 3. pp. 447-461.

8. Drumond C. E., De Jesus C.S. Monetary and fiscal policy interactions in a post Keynesian open-economy model // Journal of Post Keynesian Economics. Volume 39, 2016 - Issue 2. pp. 172-186.

9. King J.E. Kaldor and the Kaldorians / Handbook of Alternative Theories of Economic Growth. Northampton, 2010.

10. Kurz H. D., Salvadori N. The post-Keynesian theories of growth and distribution: a survey / Handbook of Alternative Theories of Economic Growth. Northampton, 2010. 
11. McCombie J. S. L., Roberts M. Effective-demand-constrained growth in a two-sector Kaldorian model // Journal of Post Keynesian Economics. Volume 31, 2008 - Issue 1. pp. 57-78.

12. Rosenbaum E. Zero growth and structural change in a post Keynesian growth model // Journal of Post Keynesian Economics. Volume 37, 2015 - Issue 4. pp. 623-647.

Поступила в редакцию 27.08.2018 